\title{
Exit 89-An Evacuation Model for High-Rise Buildings-Model Description and Example Applications
}

\author{
RITA F. FAHY \\ Fire Analysis and Research Division \\ National Fire Protection Association \\ 1 Batterymarch Park \\ Ouincy, Massachusetts 02269-9101 U.S.A.
}

\begin{abstract}
EXIT89 is an evacuation model designed to handle the evacuation of a large population of individuals from a high-rise building. It has the ability to track the location of individuals as they move through the building so that the output from this model can be used as input to a toxicity model that will accumulate occupant exposures to combustion products.
\end{abstract}

The model has been enhanced to allow the user to specify whether the occupants of the building will follow the shortest exit paths or their familiar route from the building, as well as to allow evacuation delays to be set by the user by locations and additional delays to be distributed randomly among the occupants. It allows smoke input to be read in from a smoke movement model or from user-defined blockages. EXIT89 models queueing effects by using occupant densities in building spaces to compute each occupant's walking speed.

One proposed future use for EXIT89 is as the evacuation module of Hazard I [1], allowing that software package to extend its use to larger, more complex buildings. The model described in this paper was designed to use the smoke movement data generated by one component of Hazard I and to provide the occupant location data required by the tenability model incorporated in Hazard I.

The program has been tested using data from evacuation drills in several buildings. Examples of the applications are presented in this paper. The model is written in FORTRAN.

KEYWORDS: evacuation model

\section{INTRODUCTION}

The origin and basic features of EXIT89 have been described in previous papers [2]. This paper will concentrate on a brief discussion of the framework of the model, a description of enhancements made to the model in the past year and will present three applications of the model that illustrate some of the its features.

EXIT89 was designed to model the evacuation of a large building with the capability of tracking each occupant individually. The output of this model, in combination with a fire and smoke movement model using the same building layout, can be used to predict the effects of cumulative exposure to the toxic environment present in a structure fire. In this way, it differs from other large-population evacuation models, such as network flow models, that treat the 
occupants of a building as if they were a fluid in a pipeline. Although such models are capable of predicting points of congestion and time until areas are cleared of occupants, they cannot follow the movements of individuals separately.

EXIT89 differs from evacuation models that incorporate specific occupant behaviors because the size of the population that can be handled by EXIT89 is too large to handle such a large amount of detail. Behaviors can be implicitly modeled to some degree by using some of the features recently added to the model. Delays in beginning evacuation are common in real situations, where occupants may assume that they are hearing another false alarm, or they may hesitate to respond to cues, including smoke, because no one else is reacting. Delays can also occur as a result of activities the occupants engage in before beginning to exit the building. These delays can include investigating the source of the alarm or smoke, securing files, gathering personal belongings, and notifying others of the situation. These delays can now be incorporated by setting a delay for each location in a building and having all occupants at the location wait that amount of time before beginning to leave.

Data from real evacuations have also shown that delays occur during the course of exiting the building as people seek information, gather belongings, alert others, fight the fire, etc. [3] As a first step toward simulating that occurrence, delays can now be randomly assigned to any specified proportion of the occupants of the building. Observations of exit choice during evacuations indicate that occupants of a building will often take the same route out of a building that they took coming in.[4] EXIT89 was modified to allow the user to model this behavior, rather than have all occupants follow calculated shortest routes out of the building.

A brief description of the model and its components follow and three example applications are presented to illustrate the use of these and other user options recently added to the model.

\section{PROGRAM DESCRIPTION}

EXIT89 requires as input a network description of the building, geometrical data for each room and for openings between rooms, the number of occupants located at each node throughout the building, and smoke data if the effect of smoke blockages is to be considered. The user is allowed to select among several options, including whether the occupants of the building will follow shortest paths out of the building or will use familiar routes; whether smoke data, if any, comes from a fire and smoke model or will be input as blockages by the user; whether there are any delays in evacuation throughout the building; whether there are any additional delays in evacuation among the occupants of the building and, if so, what percentage of the occupants will delay and what are the minimum and maximum delay times.

The following is a brief overview of the model. It either calculates the shortest route from each building location to a location of safety (usually outside) or sets user-defined routes through the building. It moves people along the calculated or defined routes until a location is blocked by smoke. Affected exit routes are recalculated and people movement continues until the next blockage occurs or until everyone who can escape has reached the outside.

Evacuation can begin for all occupants at time 0 or can be delayed. Additional delays over a specified range of time can be randomly assigned to occupants. Smoke data can be used to predict when the activation of a smoke detector would occur and evacuation will begin then or after some user-defined delay beyond that time. The program is written in Fortran and currently runs on an IBM mainframe.

\section{CHARACTERISTICS AND ASSUMPTIONS OF EXIT89}

The model was designed to meet the following needs for use in high-rise applications: 1) to be able to handle a large occupant population; 2) to be able to recalculate exit paths after rooms or 
nodes become blocked by smoke; 3 ) to track individuals as they move through the building by recording each occupant's location at set time intervals during the fire; and 4) to vary travel speeds as a function of the changing crowdedness of spaces during the evacuation, i.e., queueing effects.

The size of the building and its population that can be handled by EXIT89 can be expanded by modifying the size of the data arrays used by the program. The dimensions of the storage arrays currently allow for over 700 occupants in a total of over 300 nodes or building spaces during 10010 -second time intervals. These can be changed by the user to handle larger problems. Due to the naming convention for nodes that the program relies on, each floor can have up to 89 nodes and the building can have up to 10 stairways.

The model does not have a global perspective, that is, occupants are not directed along the truly shortest path out of the building. When the shortest path option is selected, people will move to the closest exit on a floor, even though the total length of the path to the outside might be shorter if another exit were used. For example, an occupant of a hotel stepping out of his room will head to the closest stairwell even though it may be five flights down to grade level while another stairwell a slightly greater distance from his room might be only three flights from grade level. A model with a global perspective would move him along the truly shortest path, but that route would not be realistic for a hotel guest who would be unfamiliar with the layout of the building.

The option that allows the user to specify that occupants will follow familiar routes can be used to model the situation where, for example, staff will know that a certain route is shorter, or a more likely case, where people will travel out the route they followed on entering the building. If a smoke blockage occurs during evacuation, the recalculation of routes for a floor will use the shortest route algorithm discussed below.

Another assumption is that once people enter a stairwell, they will follow it all the way down to the outside unless it becomes blocked by the fire's progress, in which case they will move out of the stairs and onto the nearest floor. In real situations, people may head for the roof or leave the stairs to go onto lower floors for no apparent reason.

EXIT89 does not explicitly include any behavioral considerations. These behaviors include investigation of the fire, rescue of small children, alerting or waking other capable adults and assisting other occupants who may require help. The population of a high-rise building is too large to handle so much detail for each individual, and behaviors such as investigation or rescue of other occupants are not as relevant in larger, more impersonal, buildings. These behaviors cause delays in evacuation and these behaviors can be included implicitly by using the option to add delays to all occupants at various locations and then adding additional delays to randomly selected individuals.

The model calculates walking speed as a function of density. This calculation will be discussed in more detail later.

\section{MODEL INPUTS}

The input to the model includes a network description of the building. Nodes can be rooms or sections of rooms or corridors, whichever will result in the most realistic travel paths. The nodes defined, though, should correspond to the rooms described in CFAST (the fire and smoke model to be used in the next version of Hazard I), if CFAST output will be used as the smoke data input for EXIT89.

The definition of each node includes its useable floor area, the height of the ceiling, its initial occupant load, the number of seconds occupants of that room will delay before beginning evacuation, and the node an occupant will move to if the user chooses the option of having 
occupants move along defined routes. The definition of each arc includes the distance between nodes and the width of the opening between the nodes. Arcs are bidirectional so a connection between nodes only has to be described once. Escape via windows is allowed by assigning a very large value as the distance along the arc so that that route will only be used as a last resort.

\section{USER OPTIONS}

There are six options set by the user at the beginning of the input file. The first indicates whether metric or standard measurements will be used in input and output. Internally, all calculations are done in metric scale but this option allows the simple use of evacuation data and floor plans from a variety of sources. The second option specifies the body size used as the basis of density calculations that are used to calculate velocities. These choices are described in more detail in a later section. The third option allows the user to specify whether occupants will be moving at emergency or normal (slower) speeds. This also is described more fully later.

The fourth option allows the user to determine whether the program should calculate the shortest paths between nodes or whether the user will be specifying the node to which occupants will move from each node. If the user selects specified routes, the node to which occupants of a node will move is included as part of the node description in the input. Userspecified paths will be used until a node on a floor becomes blocked by smoke. In that case, the routes for the floor will be recalculated using the shortest-route routine.

The fifth option indicates whether or not the user is reading in smoke data from CFAST or whether there will be user-defined blockages or no blockages. The use of this option is described in more detail in the next section. And finally, the user selects full output, which prints information every time someone moves from one space to another, or summary output showing floor and stairway clearing times and usage of exits.

On the next two lines, the user indicates whether or not additional delay times should be randomly distributed among the occupants. If yes, the user then specifies for what percentage of the occupants there will be additional delays and over what range of time (in seconds) those delays should be chosen.

\section{USING THE MODEL}

EXIT89 can be used in two different ways. The user can input the names of nodes that become blocked by smoke and the time those blockages occur. Or, the user can take the smoke data output from CFAST as input to the model. CFAST will calculate and write to a disk file the smoke levels of the hot upper layer at each node at each time interval and the height from the floor of the cooler lower layer. In the first version, evacuation begins simultaneously throughout the building at time 0, plus any delay time specified at nodes by the user or randomly assigned by the model. In the second version, evacuation begins throughout the building when the smoke level reaches that defined for smoke detector activation, plus any delay time specified at nodes by the user or randomly assigned by the model. By using the first version and not specifying any blockages, the user can model evacuation of a building with no fire occurring.

The program will print out the movement of each occupant from node to node. It also records the location of each occupant at each time interval so that the output can be used as input to a model such as TENAB, the tenability component of Hazard I. TENAB will calculate the hazards to which each occupant was exposed using CFAST output for combustion products and will determine when incapacitation or death occurs. The user can suppress this output and have the model only print out a summary showing floor clearing times, stairway clearing times and last time each exit was used and how many people used each exit. 


\section{SHORTEST ROUTE CALCULATIONS}

Shortest routes are calculated for each floor, from each node to the stairways or to the outside. The shortest route algorithm used is that described by Hillier and Lieberman as the shortest and simplest of those they reviewed.[5] The algorithm begins by identifying the origin of a network and then fans out from the origin, identifying the shortest routes to all the other nodes until the destination is reached.

The adapted version of the algorithm used in the model is described below. The model calculates the shortest routes on each floor to the stairways or the outside or other locations of safety. Locations of safety can include horizontal exits or areas on the other side of fire doors. In order for the model to recognize these locations of safety, the user identifies them as part of the building description input data. These nodes are referred to as intermediate exits (IE) in the following discussion. An array is created that consists of the connected node that occupants at a given node will move to in evacuating the building. For example, if the path from node 102 to the outside goes through nodes 104 and 107 , then the connected node for 102 is 104 , the connected node for 104 is 107 and the connected node for 107 is the outside. The route down each stairway is then established by defining the connected node for each stairway node as the one below it. Stairways can terminate above the ground floor. The program will continue the path of travel from the stairway through the floor onto which the stairs open.

The shortest route subroutine begins by identifying all the IE's on a floor of the building. These nodes are placed on the list of "solved nodes."

Step 1 Identify all unsolved nodes connected to the solved nodes.

Step 2 Add the distance between the solved and unsolved nodes to the distance from the solved node to its closest IE.

Step 3 The unsolved node with the shortest distance to the IE is added to the list of solved nodes, its connected node is that solved node and its distance to the IE is stored.

Return to Step 1 until all nodes are solved. This is repeated for each floor.

One advantage of the approach used in EXIT89 is that the blocking of a node by smoke will only require the recalculation of the routes on that floor, rather than all routes throughout the building. If a stairway node is blocked by fire, the routes on that floor and the floor above will be recalculated. This will cause occupants in the stairway on higher floors to move out of the stairway when they reach the node above the smoke-blocked node. Another advantage of this approach is that it more closely approximates the local perspective of an occupant in the building. Other shortest route routines "see" all possible routes to the outside and so they make decisions based on information not available to a real person.

\section{CALCULATION OF WALKING SPEEDS}

EXIT89 uses walking speeds calculated as a function of density based on formulas from Predtechenskii and Milinskii.[6] Body size is included in their density calculations. Using dimensions of people (adults, youths, and children) in various types of dress, both emptyhanded or encumbered with packages, knapsacks, baggage or babies, they calculated the area of horizontal projection of a person. This measure is the area of an ellipse whose axes correspond to the width of a person at shoulder level and breadth at chest level. Tables of mean values for different age groups and types of dress are given in the text. Their formula for density of a stream of people, $D$, is: 
where $\quad \mathrm{N}=$ number of people in the stream

$\mathrm{f}=$ the area of horizontal projection of a person

$w=$ width of the stream

$\mathrm{L}=$ length of the stream.

Their model established an optimal density of 0.92 . Although a higher density can be observed in real situations, 0.92 is the maximum they used in empirical expressions for walking speeds. Based on their observations, they developed the following equations for normal circumstances. For the mean values of velocity as a function of density for horizontal paths:

$$
\begin{gathered}
V=112 D^{4}-380 D^{3}+434 D^{2}-217 D+57 \quad(\mathrm{~m} / \mathrm{min}) \\
\text { for } 0<D \leq 0.92
\end{gathered}
$$

For movement through doors

$$
\mathrm{V}_{\mathrm{o}}=\mathrm{Vm}_{\mathrm{o}} \quad(\mathrm{m} / \mathrm{min})
$$

$$
\text { where } m_{0}=1.17+0.13 \sin \left(6.03 D_{0}-0.12\right)
$$

For movement down stairs

$V_{\emptyset}=V_{m} \quad(\mathrm{~m} / \mathrm{min})$

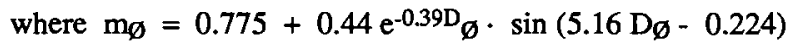

Since the model does not yet move people up stairs, the values for travel up stairs are not shown.

In emergencies, such as earthquakes or fire, the fear that makes people try to flee danger raises the speed of movement at the same densities. [6] Predtechenskii and Milinskii found the following relationship between the two velocities:

$\mathrm{V}_{\mathrm{e}}=\mu_{\mathrm{e}} \cdot \mathrm{v}$

$$
\text { where } \begin{array}{ll}
\mu_{e}=1.49-0.36 \mathrm{D} & \begin{array}{l}
\text { for horizontal paths and through openings } \\
\text { for descending stairs. }
\end{array} \\
\mu_{\mathrm{e}}=1.21 &
\end{array}
$$

Tables of velocities by density were given for normal, emergency and comfortable movement along horizontal paths, through openings and on stairs. EXIT89 currently incorporates the velocities for normal and emergency movement.

The area of horizontal projection of a person used in the calculation is $0.113 \mathrm{~m}^{2}\left(1.22 \mathrm{ft}^{2}\right)$-the mean dimensions of an adult in mid-season street dress. Velocities are calculated for both segments of the arc between two nodes, based on the different densities and floor areas for the two nodes. If a value for $\mathrm{D}$ greater than 0.92 is calculated, $\mathrm{D}$ is set equal to 0.92 . The value calculated for $\mathrm{D}$ is used to look up the velocity from the tables. The tables hold velocities along horizontal paths and down stairs.

Initially, the program was coded the way the formulas were given; that is, the density was based on the area of the stream -- the width of the doorway by the length of the stream of people. This resulted in reduced velocities even when only two people were in a room, and could noticeably decrease walking speed when, say, six people were in even a fair-sized room. People do not necessarily line themselves up so closely when evacuating through rooms. They 
can spread out and so maintain a more rapid, free-flowing walking speed. The formulas used in the model now calculate densities based on the floor area of the nodes. For travel along corridors, the useable floor area and the area of the stream as calculated by Predtechenskii and Milinskii will be very close, if not identical.

\section{BODY SIZE DATA}

Predtechenskii and Milinskii's work used body sizes calculated from the measurements of Soviet subjects. Subsequent work by Ezel Kendik using Austrian subjects found significant differences in the results.[7] The value of $0.113 \mathrm{~m}^{2}$ described above compares to the Austrian result for subjects between the ages of 10 and 15 years without coats. The value for Austrian subjects between ages 15 and 30 wearing coats was $0.1862 \mathrm{~m}^{2}$ and without coats was 0.1458 $\mathrm{m}^{2}$. The value for adults over age 30 without coats was $0.1740 \mathrm{~m}^{2}$.

A table of mean body dimensions representative of U.S. male and female workers between 18 and 45 years of age was obtained from Occupational Safety and Health in Business and Industry. From this table, mean values for shoulder breadth $(.455 \mathrm{~m}$ for men, $.417 \mathrm{~m}$ for women) and chest depth (.231 for men, .234 for women) were obtained. In order to add the additional bulk of clothing, the table of Russian data were checked. That table included values for summer dress, mid-season street dress and winter street dress. The values increased by 0.02 meters between each category of clothing. Based on this, then, the American values for shoulder breadth and chest depth were increased by 0.02 meters. To obtain one "American" value for horizontal projection of a person, the mean values for men and women were averaged. The resulting value was $0.0906 \mathrm{~m}^{2}$, far smaller than that calculated for Soviet or Austrian subjects. The choice between the three sets of data is an input option set by the user.

\section{SMOKE LEVELS}

As mentioned earlier, there are two versions of this model. In the first, the user determines at what node and when blockages due to smoke will occur. In the second version, smoke densities and depths of smoke layers are read in from a file created by CFAST. Using the same method as EXITT of calculating the psychological impact of smoke, $S$, the following equation is used:

$\mathrm{S}=2 \cdot \mathrm{OD} \cdot \mathrm{D} / \mathrm{H}$

where OD is the optical density of the smoke in the upper layer

$\mathrm{D}$ is the depth of the upper layer, and

$\mathrm{H}$ is the height of the ceiling.

EXITT uses $S>0.5$ to stop an occupant and $S>0.4$ as a threshold to prevent entering a room, in both cases unless there is enough clear air in the lower layer to crawl. Since this model does not yet handle crawling, a value of $S>0.5$ is used to block a node which traps everyone currently at that node.

Smoke detectors operate when $S \geq 0.015$ and the depth of the upper layer is greater than 0.15 $m(0.5 \mathrm{ft})$. The model currently assumes that notification of all occupants occurs when levels needed for smoke detector activation are reached at any node, and evacuation will begin after any user-specified delays.

\section{MOVING THE OCCUPANTS}

The initial routes throughout the building are calculated by the model (if the shortest route 
option is selected) or determined by the user before any smoke data is read in. For the first version of the model, where the user enters the location and time of smoke blockages, notification to begin evacuation occurs at time 0 . For the second version, the model reads in the smoke data and determines where and when blockages would occur and when smoke detector activation would occur and evacuation would begin.

The model begins by calculating, based on the initial distribution of occupants, how long it would take to travel from each occupied node to its connected node. Then for each occupant, it looks at how long that occupant has been at that node and how long it takes to traverse the arc. If the occupant has been waiting long enough to traverse the arc, the occupant is moved to the next node, and the waiting time at that node is set to 0 . Waiting times are actually portions of the arc traversal times. If there are still occupants in the building, the model recalculates time to traverse arcs based on the updated densities at nodes.

The sequence is repeated until the time is reached when a node is blocked by smoke. At that point, the affected node is removed from the network, any occupants at that node are counted as trapped and shortest routes are recalculated for the affected floor (or floors if the node is in a stairway). People movement is then resumed until the next blockage or until everyone is either out of the building or trapped.

Queueing is handled by the decreased walking speeds that result from increased densities as more occupants move into a room or stair. The program does not currently allow occupants to select less crowded routes; they simply join the queue at nodes along the shortest route.

\section{EXAMPLE 1 - COMPARISON OF EMERGENCY AND NORMAL SPEEDS}

For the first example application of the model, data from a fire drill in a nine-story office building was used. This building consists of seven floors of office space (floors 2 through 8 ). The ground floor consists of the lobby, a cafeteria and building services. There is a mechanical equipment penthouse on the top floor. Each of the office floors consists of approximately 1,950 square meters (21,000 square feet) of usable space. There are two stairwells in the central core of the building. Both discharge into the lobby. At the time of the fire drill, there were approximately 100 workers on each office floor (a total of 700 occupants).

The model was run first using the emergency velocities from Predtechenskii and Milinskii described earlier. These resulted in an estimate of 5.6 minutes to evacuate the building, faster than the 7 minutes calculated during the drill. This may not be an unreasonable result, given that the occupants of the building during the drill would not have felt compelled to treat the situation as an emergency and would not have moved throughout the building as quickly as they would if they had felt threatened.

The program was modified to use the "normal" velocities computed by Predtechenskii and Milinskii. These velocities are from 14 percent to 32 percent slower than the emergency rates. When the model was rerun using the same floor plan and occupant distribution, the time to evacuate the building increased to 10 minutes. This now is slower than the 7 minutes calculated during the drill.

\section{EXAMPLE 2 - COMPARISON OF SHORTEST AND DIRECTED ROUTES}

A second large example application of the model was done using data from a seven-story office building in Newcastle-on-Tyne (UK) [8]. The data used in this analysis were provided by the Tyne and Wear Fire Brigade and were obtained during a fire drill they conducted with the cooperation of building management. In the course of designing the fire drill, the fire brigade decided to challenge the occupants by denying the use of one of the stairways as if it were blocked by fire. They counted and timed the occupants using different exits and surveyed the 
occupants after the drill to ask them where they started, which exits they used and how long they delayed before beginning to evacuate.

There was one particularly interesting finding from the fire drill. The building is built into the side of a hill, so there are exits directly to the outside on several floors. The third floor has an exit to the parking lot at the rear of the building. The building's evacuation plan calls for the occupants to meet in that parking lot. During the evacuation, most of the occupants headed for the most direct route to the back of the building, even if that meant that they had to climb stairs or ignore closer exits that did not go there.

The model was first run using the shortest route option. The calculated time to building evacuation was shorter than that observed at the drill, but, of course, the model did not send most occupants to one exit. A comparison of the observed use of the exits and the use predicted by the model is shown in Table 1 . Exit 10 is the one that opened out to the assembly area in the parking lot. The observers reported that occupants throughout the building followed paths within the building that took them directly to the assembly area instead of taking the actual shortest route from the building and then walking around the building and up the hill to the assembly point. Congestion at Exit 10 reportedly occurred almost immediately as a result. In contrast, the model used shortest routes from each location.

Table 1. Use of Exits Observed and Calculated

\begin{tabular}{|c|c|c|c|c|c|c|}
\hline & \multicolumn{2}{|c|}{ Observed } & \multicolumn{2}{|c|}{$\begin{array}{c}\text { Predicted Using } \\
\text { Calculated Shortest } \\
\text { Routes }\end{array}$} & \multicolumn{2}{|c|}{$\begin{array}{l}\text { Predicted Using User* } \\
\text { Specified Directed } \\
\text { Routes }\end{array}$} \\
\hline & People & Last Exit & People & Last Exit & People & Last Exit \\
\hline Exit 1 & 2 & 45.0 & 2 & 35.0 & 2 & 35.0 \\
\hline Exit 2 & 6 & 48.0 & 6 & 26.0 & 6 & 26.0 \\
\hline Exit 3 & 6 & 90.0 & 107 & 148.0 & 6 & 36.0 \\
\hline Exit 4 & 40 & 105.0 & 124 & 153.0 & 51 & 104.0 \\
\hline Exit 5 & 0 & - & 7 & 72.0 & 7 & 103.0 \\
\hline Exit 6 & 23 & 115.0 & 27 & 109.0 & 26 & 95.0 \\
\hline Exit 7 & 0 & 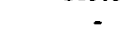 & 0 & 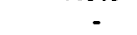 & - & - \\
\hline Exit 8 & 48 & 190.0 & 6 & 60.0 & 30 & 120.0 \\
\hline Exit 9 & 8 & 90.0 & 11 & 54.0 & 11 & 54.0 \\
\hline Exit 10 & 248 & $\begin{array}{r}220.0 \\
\text { last few at } \\
286 \text { sec. }\end{array}$ & 91 & 107.0 & 242 & 162.0 \\
\hline Total Exited & 381 & $286.0 \mathrm{sec}$ & 381 & $153.0 \mathrm{sec}$ & 381 & $162.0 \mathrm{sec}$ \\
\hline $\begin{array}{l}\text { The second run } \\
\text { xtent possible. } \\
\text { bserved results } \\
\text { vacuation is lo } \\
\text { bserved in the } \\
\text { ourse of evacu } \\
\text { ollowing exam } \\
\text { egun beyond t }\end{array}$ & $\begin{array}{l}\text { e model } \\
\text { results } \\
\text { the he } \\
\text { than for } \\
\text { uation. } \\
\text { is -- this }\end{array}$ & $\begin{array}{l}\text { nt the occu } \\
\text { also show } \\
\text { y use of Ex } \\
\text { e previous } \\
\text { le explanat } \\
\text { enomenon } \\
\text { does not c } \\
\text { from queu }\end{array}$ & $\begin{array}{l}\text { nts along } \\
\text { in Table } \\
10 \text {. Alth } \\
\text { ta set, the } \\
\text { of this c } \\
\text { as well-r }\end{array}$ & $\begin{array}{l}\text { In paths ob } \\
\text { In this cas } \\
\text { gh the pred } \\
\text { me is still } \\
\text { ld be the d } \\
\text { orted in the } \\
\text { lelays after }\end{array}$ & $\begin{array}{l}\text { erved in th } \\
\text {, both the } \\
\text { icted time } \\
\text { ne minute } \\
\text { lays that o } \\
\text { evacuation }\end{array}$ & $\begin{array}{l}\text { drill to the } \\
\text { del and th } \\
\text { complete } \\
\text { ter than th } \\
\text { ur during } t \\
\text { rills used i } \\
\text { the exit ha }\end{array}$ \\
\hline
\end{tabular}

\section{EXAMPLE 3 - RANDOMLY DISTRIBUTED DELAY TIMES}

A series of evacuations were conducted by the University of Ulster to test the effect of disabled 
persons on occupant flow in mixed ability populations.[9] Three of these evacuations took place in a hotel with two daytime scenarios and one nighttime scenario. The night and one of the day scenarios used the same fire location and these were the two evacuations for which EXIT89 was run.

The hotel wing used for the evacuation was a two-story structure with exit stairs at both ends and another stairwell in the center. One of the end stairs was made unavailable for the evacuation. Several of the occupants taking part in the evacuation were disabled. They included users of wheelchairs, canes and walkers. Although the program does not at this point differentiate between them and able-bodied occupants, these people were included among the occupants in the applications using EXIT89.

In the course of the actual evacuations, alarm bells did not consistently ring throughout the bedroom section of the hotel. In the first example, the alarm was inaudible for many of the occupants, significantly delaying their evacuation. In the second example, the alarm was at least slightly audible for all occupants.

The initial locations of the occupants for each of the evacuation exercises were provided on floor plans. Also available were the length of time it took occupants to leave their rooms and their time to leave the building. The location of cameras through the building allowed researchers to determine the duration and causes of additional delays during evacuation.

In the first daytime scenario, estimated delays in evacuating bedrooms ranged from one to 30 seconds. In addition, 14 out of 27 occupants observed by cameras delayed at some point in the corridors during their evacuation. The duration and reasons for these delays were detailed in the report. The reasons included, among others, stopping to read a notice on the foyer door (one to two second delay), holding doors open for wheelchair users (nine to 13 second delay), calling on friends (up to 30 second delay) and traveling in the opposite direction of designated escape route (up to nine second delay).

Among the 22 non-disabled occupants observed by cameras in this evacuation, the times to reach the exit ranged from 16.6 to 60.0 seconds with a mean time of 37.1 seconds. The first run of this evacuation used reported and estimated delay times in the rooms for these occupants and resulted in evacuation times that ranged from 23.1 to 60.1 seconds with a mean time of 39.5 seconds. A second run of this evacuation added random delays of one to 30 seconds to half of the occupants. In this case, the predicted evacuation times ranged from 23.1 to 79.1 seconds with a mean time of 45.8 seconds. A closer look at the movement of the occupants showed that many of the occupants actually reached the exit sooner because the delays reduced congestion in the corridors and allowed them freer and more rapid movement. Since most of the reported delays during evacuation actually lasted less than 10 seconds, the example was run a third time with random delays of one to 10 seconds distributed among half the occupants. This resulted in predicted evacuation times that ranged from 23.1 to 65.8 seconds with a mean time of 41.8 seconds.

In the nighttime scenario, observations were provided for 55 non-disabled occupants. For these people, estimated delays in evacuating bedrooms ranged from five to 78 seconds. In addition, 33 of these 55 occupants were observed to delay in the corridors during their evacuation. These delays ranged from one to 15 seconds and were due to making decisions, queueing, and assimilating information.

Among these 55 occupants, the times to reach the exit ranged from 17.3 to 90.0 seconds with a mean time of 42.6 seconds. The first run of this evacuation used reported and estimated delay times in the rooms for these occupants and resulted in evacuation times that ranged from 24.9 to 107.8 seconds with a mean time of 50.1 seconds. A second run of this evacuation added random delays of one to 15 seconds to 60 percent of the occupants. In this case, the predicted evacuation times ranged from 27.1 to 116.3 seconds with a mean time of 56.0 seconds. Since most of the reported delays during evacuation actually lasted less than five seconds, the 
example was run a third time with random delays of one to five seconds distributed among 60 percent of the occupants. This resulted in predicted evacuation times that ranged from 27.7 to 110.9 seconds with a mean time of 52.3 seconds.

In both of the actual evacuations, disabled occupants were present; however, it was found that they did not adversely impact the movement of the non-disabled evacuees.

\section{SUMMARY OF RESULTS}

The first example illustrated the difference in results that can be achieved by varying occupant speeds between emergency and normal velocities. Normal velocities should be used to simulate evacuation during drills, when building occupants do not feel compelled to move quickly as they are aware that no real threat exists. It can also be used to simulate real fire situations where occupants may also not feel directly threatened and so are not in hurrying to exit the building. Changing body sizes, which will effect the density calculations, can also be used to adjust walking speeds.

The second example illustrated the use of directed vs. shortest routes. The results were fairly good but the differences between observed and calculated exit times show that movement is more efficient as calculated by the model than as actually occurs. This is because the model does not include the stop-and-go movement that occurs among real people as they change direction along their exit path, wait for friends, try the elevators and engage in any of a wide range of activities that delay them along their routes. An attempt to handle some of the additional delays was incorporated in the next example.

The third example was based on a series of exercises that documented some of those delays in evacuation, their causes and duration. These delays were then incorporated in the simulated runs as delays in starting evacuation. Again the results were fairly good. Delaying some people at random allowed others to evacuate more quickly than they did in the first run of this application. Although there were disabled people present in the real tests, it was found by the researchers that their presence did not impede the able-bodied occupants. They were not included in the simulation runs because at this point disabled occupants cannot be modeled.

\section{CONCLUSION}

The model in its current form does not include any explicit behavioral considerations but it does allow behavioral considerations to be handled implicitly by incorporating time to perform investigation activities or to alert others before evacuating in the delay times that the user specifies for the occupants of each node. In addition to specifying delay times for each location, the user now can also have the computer randomly assign additional delays to some percentage of the individuals throughout the building. In this same way, another behavior that can be dealt with implicitly is the tendency of able-bodied adults in the presence of other ablebodied adults to ignore early warnings of the presence of a fire.

EXIT89 now allows the user to model the frequently observed tendency of occupants to follow the route out of the building that they are most familiar with, not the shortest paths out of building which often would involve the use of emergency exits. These familiar paths defined by the user will remain in place until a location on that floor becomes blocked by smoke and the routes on that floor need to be recalculated using the shortest route algorithm.

Walking speeds are calculated as a function of densities and are based on tables of values from Predtechenskii and Milinskii. The model does not yet simulate crawling through smoky rooms by reducing walking speeds, or reversing direction where possible to use a less smoky, though longer escape route. Also to be included is the simulation of disabled people, who can be incorporated using added size (in order to impact density) as well as slower speeds. The 
University of Ulster has provided much useful information for incorporating this modification.

One of the program's inputs is the capacity of nodes. The reason for including this value was to allow evacuees to avoid nodes that were already crowded if alternate routes are available. This would prevent occupants from queueing at one stairway while the other section or sections of the floor emptied out into less busy stairways. Refinements of the program to define and possibly limit the range of a smoke detector also need to be added to the model.

Future plans for the model include adding a component for disabled occupants and documenting from available literature travel speeds and the delay times that can be used for occupants to begin evacuation and for delays during evacuation. These travel speeds and delay times may be occupancy-specific. Testing of the model using data from actual emergency and non-emergency evacuations will also continue.

\section{ACKNOWLEDGEMENTS}

This work has been sponsored in part by the National Institute of Standards and Technology Building and Fire Research Laboratory under Grant No. 60NANB2D1286.

\section{REFERENCES}

1. Bukowski, R.W., Jones, W.W., Levin, B.M., Forney, C.L., Steifel, S.W., Babrauskas, V., Braun, E. and Fowell, A.J., "HAZARD I - Volume I: Fire Hazard Assessment Method," National Institute of Standards and Technology Center for Fire Research, NBSIR 87-3602, July 1987.

2. Fahy, R.F., "EXIT89: An Evacuation Model for High-Rise Buildings," Proceedings of the Third International Symposium, International Association for Fire Safety Science, Elsevier Science Publishing Co., Inc., New York, 1991, and Proceedings Interflam 93, Interscience Communications, Ltd., London, 1993.

3. For examples, see Fires and Human Behaviour, edited by D. Canter, 2nd ed., David Fulton Publishers, Ltd., London, 1990.

4. Kimura, M. and Sime, J.D., "Exit Choice Behaviour during the Evacuation of Two Lecture Theatres," Proceedings of the Second International Symposium, International Association for Fire Safety Science, Hemisphere Publishing Corporation, New York, 1989.

5. Hillier, F.S. and Lieberman, G.J., Introduction to Operations Research, 3rd ed., Holden-Day, Inc., Oakland, California, 1980.

6. Predtechenskii, V.M. and Milinskii, A.I., Planning for Foot Traffic Flow in Buildings, Amerind Publishing Company, Inc., New Delhi, 1978.

7. Kendik, E., "Assessment of Escape Routes in Buildings and a Design Method for Calculating Pedestrian Movement," SFPE Technology Report 85-4, Society of Fire Protection Engineers, Boston, Massachusetts, 1985.

8. Butler, G.W., "The Factors Involved in Evacuation and the Extent to Which Efficient Management Can Influence These," Proceedings - Interflam '93, Interscience Communications, Ltd., London, 1993.

9. Shields, T.J., "Fire and Disabled People in Buildings," Building Research Establishment Report BR 231, Building Research Establishment, Garston, 1993. 